\title{
Morphological and Molecular Characterization of Toxocara apodemi (Nematoda: Ascarididae) from Striped Field Mice, Apodemus agrarius, in Korea
}

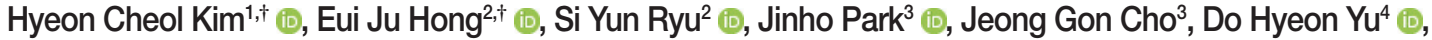 \\ Joon Seok Chae ${ }^{5}$ id, Kyoung Seong Choi ${ }^{6}$ (D), Bae Keun Park ${ }^{2, *}$ (D) \\ College of Veterinary Medicine and Institute of Veterinary Science, Kangwon National University, Chuncheon 24289, Korea; ${ }^{2}$ College of Veterinary \\ Medicine, Chungnam National University, Daejeon 34134, Korea; ${ }^{3}$ College of Veterinary Medicine, Chonbuk National University, Iksan 54596, \\ Korea; ${ }^{4}$ College of Veterinary Medicine, Gyeongsang National University, Jinju 52828, Korea; ${ }^{5}$ Laboratory of Veterinary Internal Medicine, BK21 \\ PLUS Program for Creative Veterinary Science Research, Research Institute for Veterinary Science and College of Veterinary Medicine, Seoul \\ National University, Seoul 08826, Korea; ${ }^{6}$ College of Ecology and Environmental Science, Kyungpook National University, Sangju 37224, Korea
}

\begin{abstract}
Adult ascarid worms from the field mice, Apodemus agrarius, were observed with a light and scanning electron microscope, and molecularly analized with 18S rRNA gene. In the scanning electron microscope, 3 prominent labia were present in the anterior end of male and female worms, but the interlabia and gubernaculum were absent. Scanning electron micrographs showed cervical alae as vestigial organs that looked like a slightly uplifted superficial sewing stitch. Total 6 pairs of post-cloacal papillae were observed on the tail of the male worms. The tail of female worms was blunt and conical shape with a spine-like structure, mucron. The eggs were sub-globular, coated with the albuminous layer and 73 by $82 \mu \mathrm{m}$ in average size. The superficial pits of $T$. apodemi egg (mean $8.6 \times 6.7 \mu \mathrm{m}$ ) are obviously bigger than those of Toxocara spp. The partial sequence of $18 \mathrm{~S}$ rRNA showed the sequence homology of Toxocara canis (99.6\%), Toxocara cati (99.4\%), Toxascaris leonina (99.4\%), and Toxocara vitulorum (99.2\%). Conclusively, it was confirmed that ascarid nematodes, Toxocara apodemi, recovered from striped field mice in Korea are taxonomically conspecific relationship with genus Toxocara and genetic divergence from other Toxocara species.
\end{abstract}

Key words: Apodemus agrarius, Toxocara apodemi, molecular characterization, scanning electron microscopy, Korea

\section{INTRODUCTION}

The 2 genera, Toxocara and Neoascaris, of the superfamily Ascaridoidea have a close morphological relationship, the genetic and morphological differentiations between 2 genera incompletely remain yet [1]. The subfamily Toxocarinae is morphologically characterized by a ventriculus without appendices and the absence of gubernaculum. Additionally, the members in the genus Toxocara does not have the intestinal cecum and interlabia [2]. And then in the species identification of the genus Toxocara, some morphological characteristics, i.e., the shape of cervical alae in the cross-sectional samples, the spicule length and lip structure act as the differential keys [3]. Ac-

- Received 3 March 2020, revised 22 July 2020, accepted 27 July 2020.

*Corresponding author (bkpark@cnu.ac.kr)

${ }^{\dagger}$ These authors contributed equally to this work.

(c) 2020, Korean Society for Parasitology and Tropical Medicine

This is an Open Access article distributed under the terms of the Creative Commons Attribution Non-Commercial License (https://creativecommons.org/licenses/by-nc/4.0) which permits unrestricted non-commercial use, distribution, and reproduction in any

medium, provided the original work is properly cited. cording to the morphological characteristics of the genus Toxocara reported by Warren [1], this nematode group with genus Toxascaris are differentiated from genus Ascaris by the arrowshape head, and they are separated each other by the egg shape. The eggs of Toxocara spp. have corrugated shells but those of Toxascaris have smooth shells.

More than 28 species including some synonyms have been reported in the genus Toxocara from a variety of host animals [3-13]. Most of these parasitize in terrestrial mammals except for T. pearsel, which is a parasite of snapping shrimp, Synalpheus brooksi $[3,14]$. At least 5 species, i.e., T. canis from canids, T. cati from felids, T. vitulorum from ruminants, T. pteropodis from bats and T. malaysiensis from cats, are known to be the zoonotic agents $[4,5]$. Another species of Toxocara have been reported in bats (T. cynonycterides), canids (T. marginata), carnivores (T. alienata, T. anakumae, T. herpestum, T. paradoxura, T. sprenti, T. suricattae, T. tanuki and T. vajrasthirae), elephants ( $T$. elephantis), felids (T. canarisi, T. genettae and T. lyncis), hippopotamus (T. hippopotami and T. vincenti), ruminant (T. manza- 
diensis and T. warren), and rodents (T. apodemi, T. indica and T. mackerrasae) respectively.

Among the toxocarid nematodes, T. canis and T. cati are most commonly found from the intestines of dogs and cats worldwide $[15,16]$. A variety of Toxocara species is commonly found in livestock, but their available scientific informations are not enough, especially about a toxocarid from wild field mice, Apodemus agrarius. Toxocara apodemi was first reported from the intestine of the wood mouse, Apodemus peninsulae from the Central National Forest, Bupyeong-ri, Namyangju-si, Gyeonggi-do, Korea [13]. This nematode was reported as a new species of the genus Neoascaris, and named as Neoascaris apodemi by Olsen in 1957. Later, this species of nematode was found in the small intestine of striped field mice in China and emended as T. apodemi [6], although it was more or less small than N. apodemi [13].

Traditionally, Toxocara spp. have been identified and classified based on their morphological features and host species [13]. Also, DNA sequencing is recently used with identification for Toxocara species [17]. Nevertheless, there is no reports for identification of $T$. apodemi by scanning electron microscopy (SEM) study and genetic information. The present study provides the first SEM data about the morphology of T. apodemi and its genetic characterization using $18 \mathrm{~S}$ rRNA analysis.

\section{MATERIALS AND METHODS}

\section{Examined animals and morphological examination}

A total of 70 wild rodents (56 A. agrarius, 4 A. peninsulae, 8 Mus musculus, and 2 Rattus norvegicus) were captured at 7 sites (Yeongdeok-gun, Uljin-gun and Sangju-si in Gyeongsangbukdo, Hapcheon-gun in Gyeongsangnam-do, Yeongwol-gun in Gangwon-do, Buan-gun, and Iksan-si in Jeollabuk-do) of Korea between March and September 2019 (IACUC No. SNU190524-2). Adult parasites were collected from the intestines after necropsy. The ascarid eggs were isolated from the uterus of a female worm and observed under a phase-contrast microscope. For the SEM of eggs, the eggs dehydrated in graded series of ethyl alcohol were sprinkled on the single side of double faced adhesive tapes, dried in a $\mathrm{CO}_{2}$ critical point dryer, and coated with gold. For turning transparent, the worms were placed in lacto-phenol solution $(20 \mathrm{ml}$ glycerin, $10 \mathrm{ml}$ lactic acid, $10 \mathrm{ml}$ phenol, and $10 \mathrm{ml}$ distilled water) for $24 \mathrm{hr}$ and observed under a phase-contrast microscope. For the SEM study, the transparented worms were washed 5 times with 0.2
M cacodylate buffer (pH 7.3), fixed in 2.5\% glutaraldehyde, and subjected to post-fixation treatment with $1 \%$ osmium tetroxide at $4^{\circ} \mathrm{C}$. The specimens of worm were dehydrated in graded series of ethyl alcohol, dried in a $\mathrm{CO}_{2}$ critical point dryer (CPD 030, BAL-TEC, Los Angeles, California, USA), coated with gold, and finally examined by SEM (XL30 ESEM TMP, Philips, Praha, Czech Republic) at $15 \mathrm{kV}$.

\section{Sequence and phylogenetic analyses}

Genomic DNA was extracted from 6 parasites using the DNeasy ${ }^{\circledR}$ Blood and Tissue Kit (Qiagen, Alameda, California, USA) according to the manufacturer's instructions. Based on the common 18S ribosomal RNA gene sequences of T. canis (JN256977 and U94382), primers were designed using the online tool Primer3 Input (version 0.4.0, http://bioinfo.ut.ee/ primer3-0.4.0/). The sequences of the primers used to detect the genus Toxocara were as follows: 5'-GCTAATACATGCACCAAAGC-3' (forward primer) and 5'-GATCACGGAGGATTTTCAAC-3' (reverse primer). The primer sets were designed to amplify an amplicon of 1,374 bp and were variable for all sequences aligned. PCR was performed using a MyCycler Personal Thermal Cycler (Bio-Rad Laboratories, Hercules, California, USA) using EmeraldAmp GT PCR Master Mix (Takara, Shiga, Japan) with $1 \mu \mathrm{l}$ of DNA under standard conditions of $95^{\circ} \mathrm{C}$ for $30 \mathrm{sec}$, annealing at $57^{\circ} \mathrm{C}$ for $30 \mathrm{sec}$, and extension at $72^{\circ} \mathrm{C}$ for $1.5 \mathrm{~min}$ for 30 cycles and additional extension at $72^{\circ} \mathrm{C}$ for $10 \mathrm{~min}$. The PCR products were visualized via electrophoresis on 1.2\% agarose gel, and then purified using the QIAquick PCR Purification Kit (Qiagen). PCR amplicons were sequenced using the ABI Prism Big Dye terminator v. 3.0 ready reaction cycle sequencing kits (Applied Biosystems, Foster City, CA, USA) with the sequencing primer (5'-CCTTCCATTTGCATGTTG-3'). After trimming the nonspecific sequencing data, the 1,351 bp sequences were aligned using Clustal Omega program (Clustal O). A phylogenetic tree based on sequence analysis was constructed by the neighbor-joining (NJ) method using the program BLAST tree. The NJ method was based on a guide tree as pairwise and multiple alignment parameters [18].

\section{RESULTS}

\section{Samples collected}

Total 9 ascarid nematode worms ( 4 males, 4 females, and 1 juvenile) were harvested in the small intestines of $5 \mathrm{~A}$. agrarius 
(8.9\%), which were captured in Yeongdeok-gun and Uljingun, Gyeongsangbuk-do, and Iksan-si, Jeollabuk-do, Korea.

\section{Morphology of both sexes}

The ventriculus lacked an appendix (Fig. 1A) and the cervical alae were the vestigial organs that looked like an uplifted sewing stitch on the proximal portion of labia and an simple sewing stitch on the distal portion of labia (Fig. 2A, D, E, F).

Figs. 2 and 3 (female) and Fig. 4 (male) show the SEM images illustrating the characteristic features of the adult worm. In adults of both the sexes, the anterior end had 3 prominent labia, which are characteristic feature of the ascarid nematodes; 1 dorsal and 2 subventral labia, surrounding the oral aperture with a median groove running longitudinally along its inner length; the interlabia was absent (Fig. 2A-C). The labia of both sexes were similar in shape, structure, and organizations, except that they were larger in the females. Three lips had 4 relatively large papillae. The dorsal labium had 2 large papillae at the dorsolateral portion, while each subventral labium had a large externolateral papilla and an amphid (Fig. 2A, B). The amphids, lateral to the externolateral papillae, appeared as small domed areas with a central pore (Fig. 2B). The conspicuous and strong dentigerous ridges were present on all labia (Fig. 2A-C). The lips had a superficial median notch lined with the denticles of the dentigerous ridge (Fig. 2B, C). The strong denticles were distributed consistently and was particularly evident in en face view (Fig. 2B, C). The triradiate oral aperture was located at the base of the stoma (Fig. 2A) and the esophagus was claviform. The posterior end of the esophagus was separated from the rest of the esophagus in form of a welldefined muscular bulb formed by a conspicuous constriction. The cuticle was finely cross striated throughout the body (Figs. $2 \mathrm{D}, \mathrm{E}$, and $3 \mathrm{~A})$.

\section{Morphology of female}

Adult females measured 61 and $67 \mathrm{~mm}$ in length and 2.15 and $2.61 \mathrm{~mm}$ in width at mid-body. The esophagus was 2.85 $3.25 \mathrm{~mm}$ long and $0.42-0.51 \mathrm{~mm}$ at maximum width. The esophageal bulb measured 0.45-0.50 mm long and 0.42-0.50 $\mathrm{mm}$ wide. The ventriculus lacked an appendix (Fig. 1A). The excretory pore was represented by a slit which is situated at the ventriculus (Fig. 1A). The vulva was located about $3 / 10$ of body length from the anterior end (for example, if the body were $52 \mathrm{~mm}$ long, the vulva opened $15.2 \mathrm{~mm}$ from the anterior end). The phasmid pore was located laterally behind the cloaca (Fig. 3A). The tail of the female slightly was blunt and bent to the ventral side. The tail was terminated in a conical shape with a retractile spine-like structure (Figs. 1C, 3B). Eggs
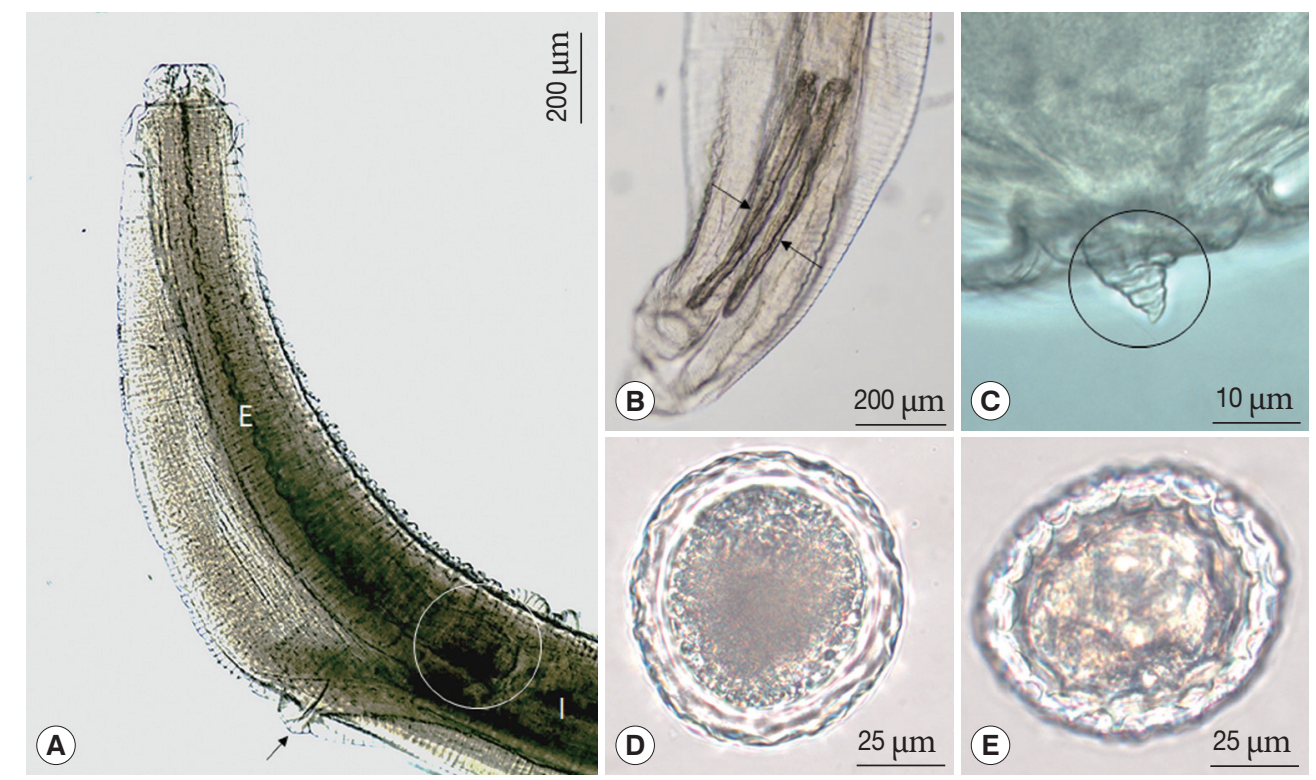

Fig. 1. Light micrographs of Toxocara apodemi. (A) Anterior end of female with ventriculus (circle) and excretory pore (arrow). (B) Posterior end of male with 2 spicules (arrows). (C) Posterior end of female. Note the blunt tail terminating in a conical shape with a retractile spine-like structure (circle). (D, E) Egg. Note outer surface of the egg was marked with a network of ridges. E, esophagus; I, intestine. 


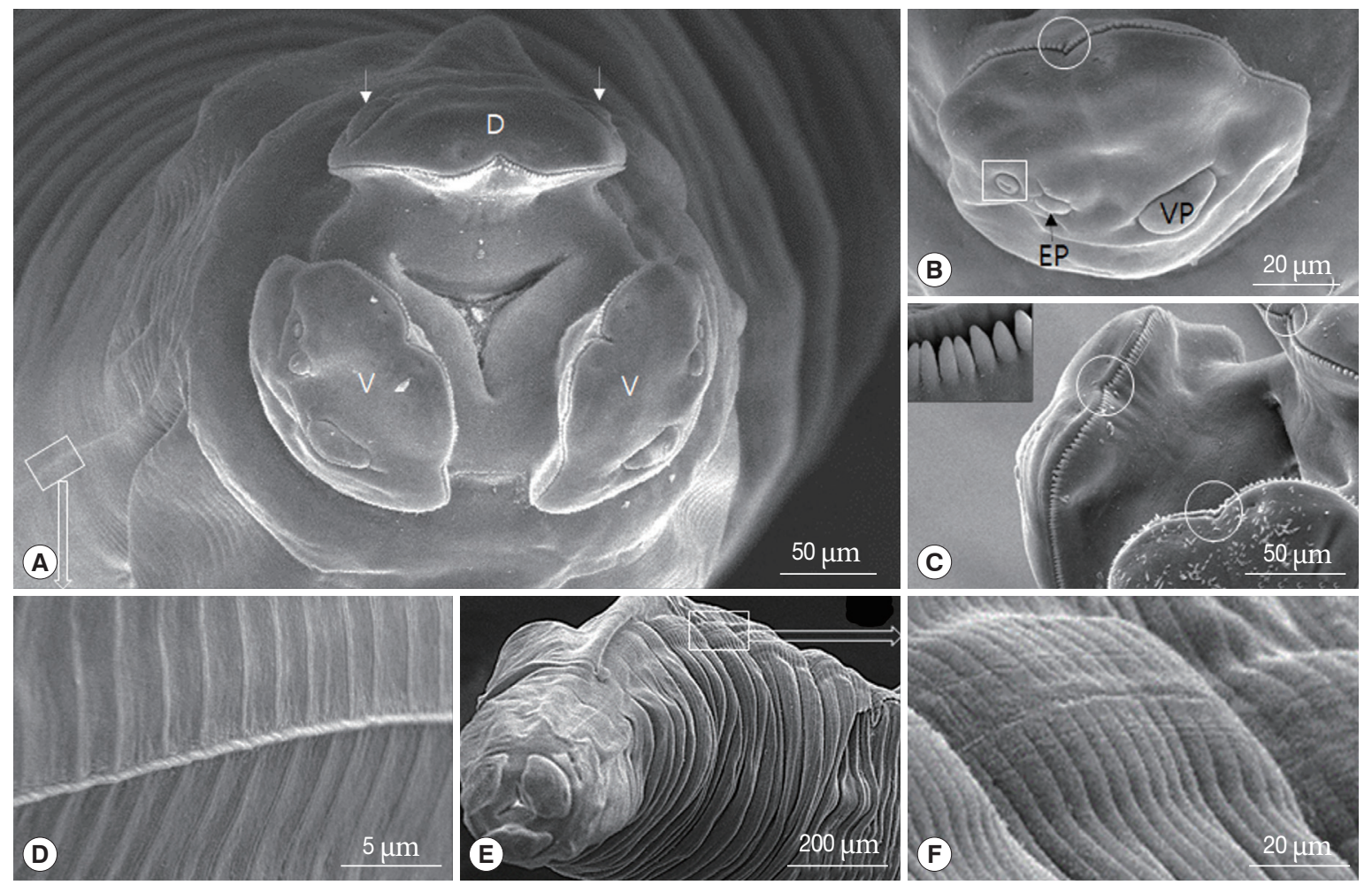

Fig. 2. Scanning electron micrographs of female Toxocara apodemi, anterior end. (A) Frontal view showing one dorsal labium, 2 subventral labia and oral aperture. Dorsal papillae (arrow head). (B) Subventral labium. Amphid (square), subventral papilla and externo-lateral papilla. Superficial median notch (circle). (C) Inner surface of dorsal labium and superficial median notch (circles). Strong tooth (square). (D) Cervical ala, which is located on the proximal labium, appear like a vestigial organ. (E, F) Cervical ala which is located on the distal labium. D, dorsal labium; EP, externo-lateral papilla; V, subventral labium; VP, subventral papilla.

were oval and measured 73-82 $\mu \mathrm{m}$ (mean $78.8 \mu \mathrm{m}, \mathrm{n}=10$ ). The outer surface of eggs was coarsely pitted and had a mosaic pattern formed by a network of ridges (Fig. 1D, E). SEM findings revealed that the surface of the egg was covered by weblike albumin and consists of numerous pits surrounded by elevated albumin (Fig. 3C, D). The mosaic pits were measured 7.3-12.8 $\mu \mathrm{m}$ 7.3-12.8 $\mu \mathrm{m} \times 5.7-7.3 \mu \mathrm{m}$ 5.7-7.3 $\mu \mathrm{m}$ (mean 8.6×6.7 $\mu \mathrm{m})$.

\section{Morphology of male}

Adult males measured $47-52 \mathrm{~mm}$ (mean $50.7 \mathrm{~mm}$ ) in length and 0.9-1.4 mm in width at mid-body. The esophagus was $2.4-2.6 \mathrm{~mm}$ long and $0.26-0.45 \mathrm{~mm}$ at the maximum width. The tail was $0.17-0.27 \mathrm{~mm}$ long and the gubernaculum was absent (Fig. 1B). The spicules were subequal and were $0.45-0.53 \mathrm{~mm}$ long (Fig. 1B). The caudal end was ventrally curved, displaying 12-14 pairs of proximal pre-cloacal papillae arranged in subventral lines (Fig. 4A). The subventral lines were arranged as double parallel lines. Pre- and post-median cloacal papillae were not observed (Fig. 4A, E). Postcloacal papillae were numbered from the cloacal opening posteriorly.

There were 6 pairs of postcloacal papillae: 3 pairs of postcloacal latero-ventral papillae (1st, 2nd, 6th pairs) and 3 pairs of postcloacal latero-dorsal (3rd, 4th, 5th pairs) (Fig. 4A, C, D). The papillae were distributed as follows: the 1st pair of postcloacal latero-ventral papillae, which were doubled, was located on each side behind the cloacal opening and the 2nd pair was located right behind them. The 3rd, 4th, and 5th pairs of postcloacal latero-dorsal papillae were located latero-dorsally beyond the cross lateral line. Further, the 3rd and 4th postcloacal latero-dorsal papillae were closely associated with each other, and the 4th pair was smaller than other papillae (Fig. $4 \mathrm{D})$. The phasmid, which was much smaller than the papillae ( $<3 \mu \mathrm{m}$ in diameter), was located laterally between the 4 th and 5th pairs of postcloacal latero-ventral papillae (Fig. 4-D). Like the rest of the body, the distal end of the tail formed a conical appendage that was transversely striated and terminated in a mucron (Fig. 4A, C, D). 

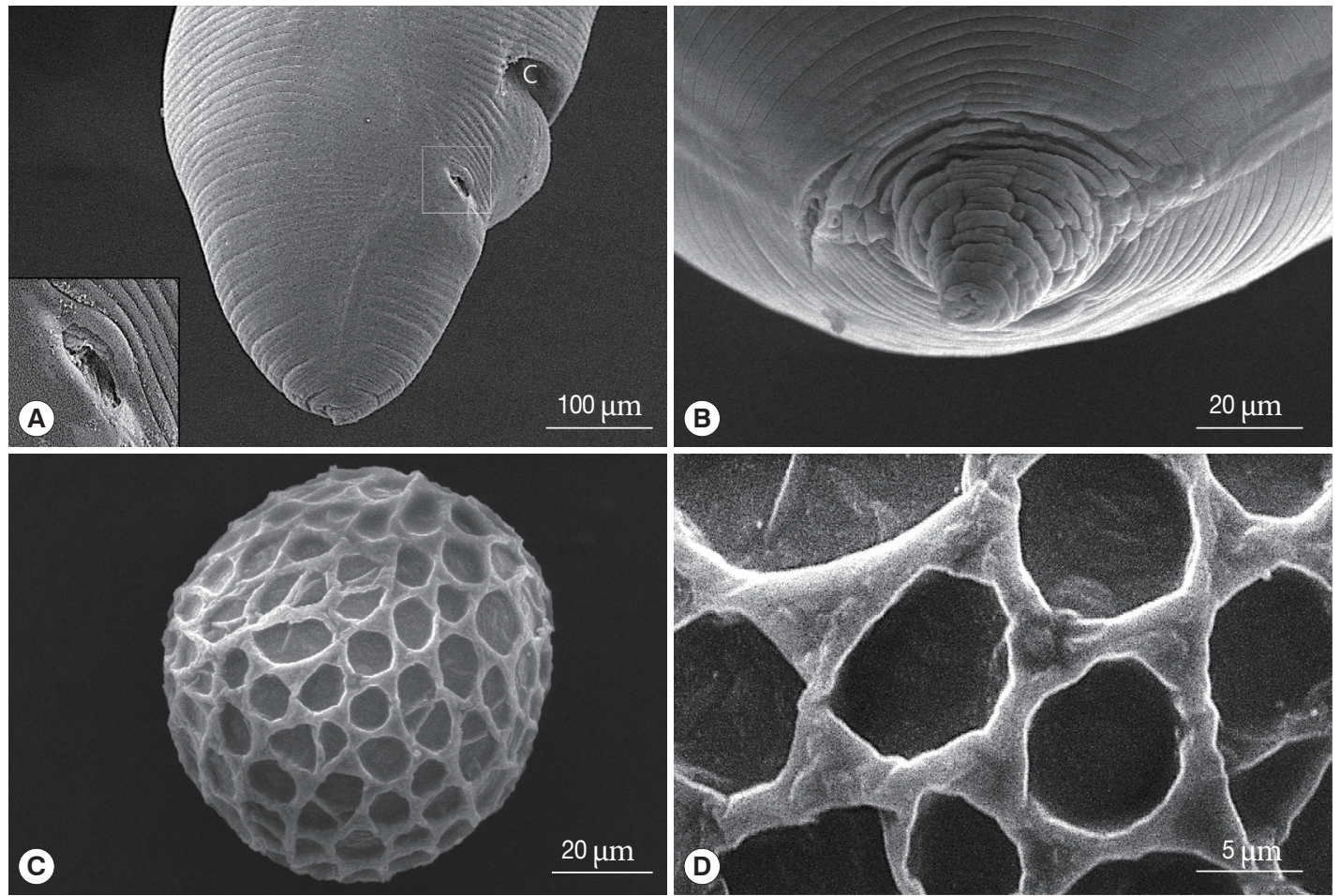

Fig. 3. Scanning electron micrographs of female Toxocara apodemi. (A) Lateral view of the posterior end. C, cloaca Phasmid pore highlighted in an insert. (B) Ventral view of the posterior end. Terminal spike. (C) Egg. Note the characteristic superficial pits. (D) Magnified surface of egg. Note the elevated albumin coat.
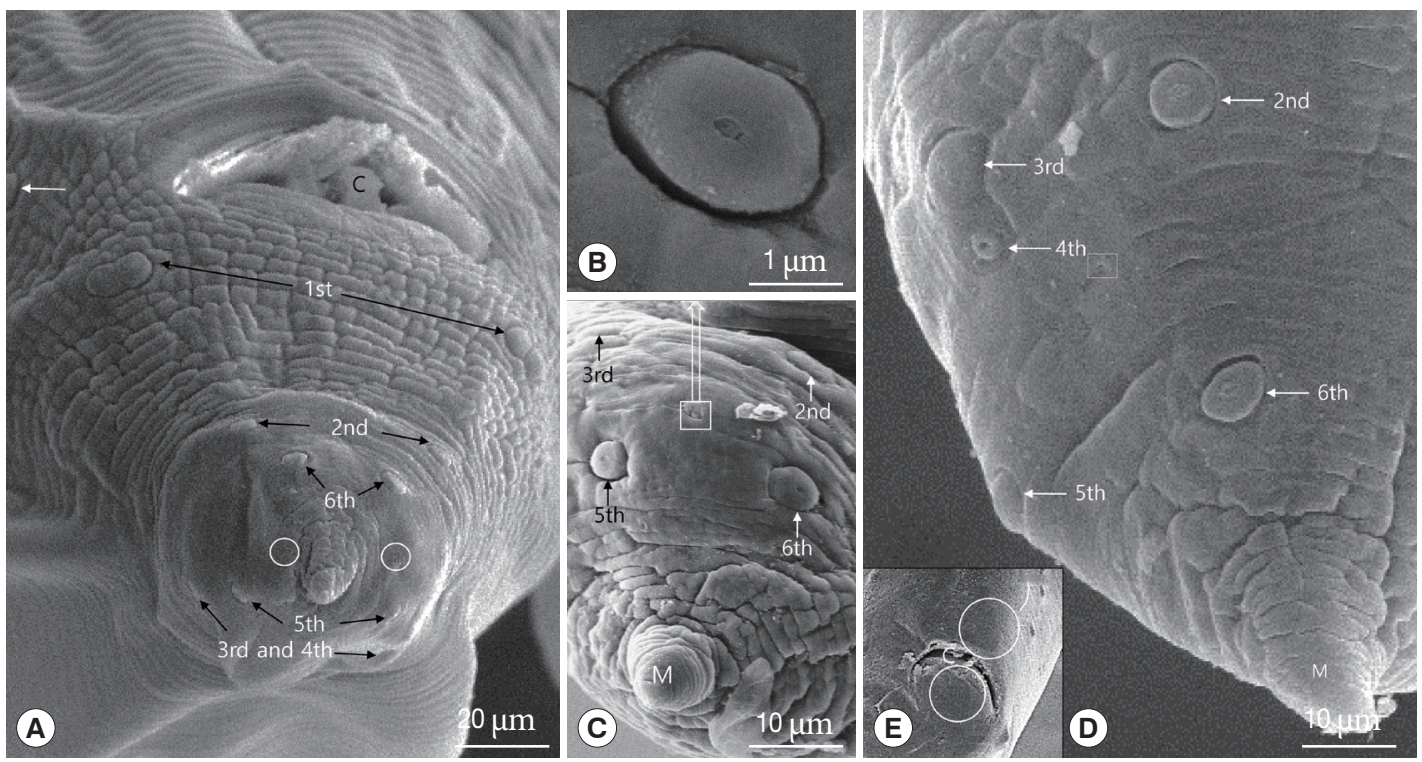

Fig. 4. Scanning electron micrographs of male Toxocara apodemi, posterior end. (A) Ventro-frontal view, a pre-cloacal papillae (white arrow) and post-cloacal papillae (numbered). The 1st post-cloacal papillae are doubled. The 1st, 2nd, and 6th post-cloacal papillae located latero-ventrally. The 3rd, 4th, and 5th post-cloacal papillae located latero-dorsally. Phasmid pores (circles) lateral in position. (B) Phasmid. (C) Latero-frontal view. The 2nd to 5th post-cloacal papillae and phasmid. The phasmid is small and lateral in position. (D) Lateral view. Positions of papillae and phasmid pores (square). (E) Ventral view. Note that the precloacal and postcloacal median papillae in circles are not observed. C, cloaca; M, mucron. 


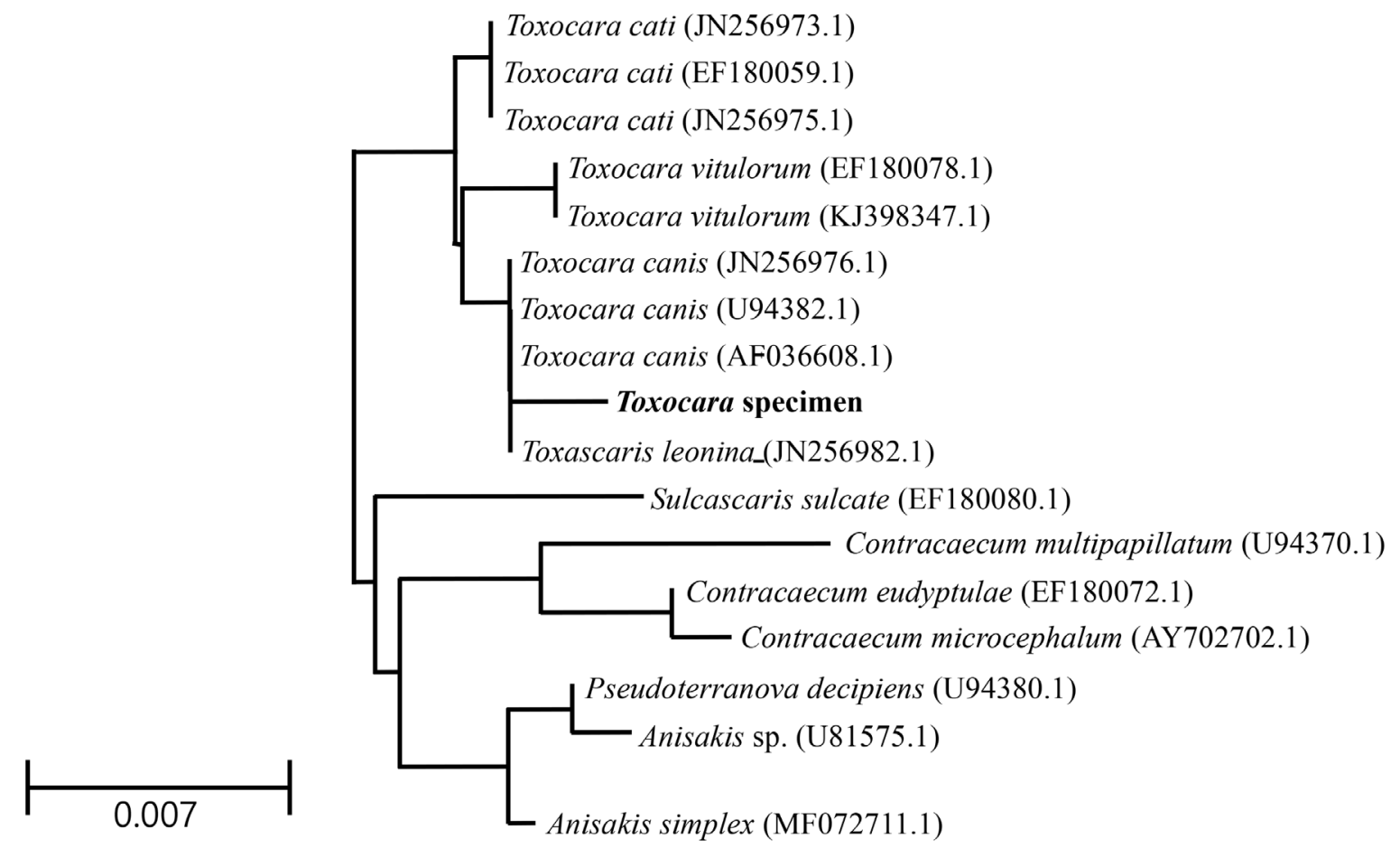

Fig. 5. A phylogenetic tree (Neighbor Joining) based on $18 \mathrm{~S}$ rRNA sequences.

\section{Molecular characteristics and phylogenetic position}

The genotype and phylogenetic relationship with other Toxocara species were determined using molecular characterization of the 18S rRNA gene. The sequencing information was registered into GenBank and received the accession number (MT460393.1) for Toxocara specimens. The partial sequences (1,351 bp) of the Toxocara specimens contained 2 unique gaps apart from sequences of genus Toxocara, including T. canis, T. cati, T. vitulorum, and Toxascaris leonina. The partial sequences also had 3 to 8 variable sites compared to aligned sequences. Results of the partial sequences showed the sequence homology of the $18 \mathrm{~S}$ rRNA gene to that of T. canis $(99.6 \%)$, T. cati (99.4\%), Ta. leonina (99.4\%), and T. vitulorum (99.2\%) (Fig. 5). After the sequence of Toxocara specimens was compared with several genes, the sequence data were inferred using the NJ method (Fig. 5). Interestingly, the partial sequences of the $18 \mathrm{~S}$ rRNA gene of Toxocara specimens showed high similarity to those of the parasite Sulcascaris sulcate (98.4\%, EF180080.1), Contracaecum multipapillatum (98.3\%, U94370.1), Contracaecum eudyptulae (98.0\%, EF180072.1), and Contracaecum microcephalum (98.0\%, AY702702.1).

\section{DISCUSSION}

The subfamily Toxocarinae is characterized by the presence of a ventriculus without appendices and the absence of interlabia and gubernaculum [2]. In this study, the nematodes did not have intestinal cecum, interlabia, appendices of ventriculus, or gubernaculum. Also, the parasites were isolated in $A$. agrarius captured from 3 areas (Uljin-gun and Yongduk-gun in Geongbuk-do and Iksan-city in Chonbuk-do). The Toxocara spp. of Muridae include T. apodemi and T. mackerrasae [1,13]. They differ in their selection of hosts; the T. mackerrasae infects Rattus fuscipes and Hydromys chrysogaster, while T. apodemi infects A. peninsulae and A. agrarius. T. apodemi was reported to infect A. peninsulae and A. agrarius in China $[6,9,13]$. Currently, in Korea, T. apodemi infects A. peninsulae and A. agrarius.

The diagnostic keys for Toxocara created by Warren [1] indicate that the external prolongations of labial pulp in T. apodemi are symmetrical and rounded at the anterior border. The terminal spike on the tail of the female is present in T. apodemi but not in T. mackerrasae. The spicules of T. apodemi are 0.55 $\mathrm{mm}$ long in males $35.0 \mathrm{~mm}$ and $0.65 \mathrm{~mm}$ long in 35 to 36 $\mathrm{mm}$ long. The measurements of spicules of other species, including T. mackerrasae (0.65 mm), T. tanuki (3.0-3.5 mm), T. 
cati (1.71-1.90 mm), T. canis $(0.91-0.97 \mathrm{~mm})$, T. pteropodis (0.58-0.73 mm), T. vincenti (0.68 mm), T. paradoxum (2.71-3.12 $\mathrm{mm})$, T. pearsei (1.2-1.32 mm), T. malysiensis (right 0.46-0.68 $\mathrm{mm}$ and left 0.48-0.76 mm), T. lyncis (1.3-1.8 $\mathrm{mm})$, and $T$. hippopotami (0.83-1.01 $\mathrm{mm}$ ) have been reported [1,3,8,11]. In this study, the spicules were subequal and measured 0.45-0.53 $\mathrm{mm}$ long. The spicules were smaller than that of other species but closer to T. apodemi (0.45-0.54 mm) [13].

The 3 labia in this study were present as in ascaridoid nematodes and the denticles had a consistent distribution and a triangular outline of labium; however, T. malaysiensis has a deep median notch lined with denticles of the dentigerous ridge, which is absent in the most toxocarids, such as T. canis, T. cati, and T. tanuki $[1,11]$. In this study, the specimen also has strong denticles on the dentigerous ridge and a superficial median notch on each lip.

Gibbons et al. [3] reported a new species, T. malaysiensis, based on the following features: presence of the esophagus with a ventriculus without an appendix, the absence of an intestinal cecum, prominent dentigerous ridges on each of the 3 lips, a V-shaped supporting bar in the cervical alae, male with sub-equal, alate spicules, female with vulva opening in the anterior half of the body, and sub-globular eggs with a thick pitted shell. Toxocara spp., including T. canis, T. cati, T. hippopotami, T. lyncis, T. malaysiensis, T. pteropodis, T. tanuki, and T. vincenti, have cervical alae $[3,6,8]$, while T. indica and T. apodemi do not have cervical alae $[12,13]$. T. indica differs from all the known species of the genus Toxocara in having subequal spicules and the absence of cervical alae, except T. alienta and T. apodemi. T. indica resembles T. alienate in the absence of cervical alae [12]. Asakawa et al. and Olsen $[6,13]$ reported that T. apodemi lacks cervical alae. However, our SEM images showed cervical alae as vestigial organs that looked like a slightly uplifted superficial sewing stitch.

The major and minor axes of T. canis eggs measure 71.6-91.2 $\mu \mathrm{m}$ by 63.4-79.0 $\mu \mathrm{m}$, T. cati eggs measure 63.7-88.1 $\mu \mathrm{m}$ by 53.3-73.3 $\mu \mathrm{m}$, and $T$. malaysiensis eggs measure $60-68 \mu \mathrm{m}$ by $68-76 \mu \mathrm{m}[3,19]$. In our study, the eggs measured $73-82 \mu \mathrm{m}$. Although the eggs observed in this study were smaller than the T. canis eggs and bigger than T. malaysiensis eggs, other significant differences were not observed. SEM images showed that the Toxocara eggs with an elevated albuminous coat were similar in shape to those of other members of the genus Toxocara [19]. Further, the surface of the egg observed in our study was coarsely pitted and covered with elevated albumin, similar to that of other toxocarids [1].

The tail of the male has a curved posterior end that distinguishes it from the straight-tailed female. The posterior end of the female is terminating in a conical shape with a retractile spine-like structure in T. apodemi and T. indica, but that of other species (i.e., T. malaysiensis, T. lyncis, T. tanuki) are conical $[1,3,8,11,12]$. Similar to $T$. indica, the sampled individuals had 6 pairs of postcloacal papillae, as opposed to the 5 pairs observed in T. tanuki and T. vitulorum $[11,12]$. Further, we observed that the posterior end of the female had a conical, retractile spine-like structure, which is a characteristic feature of T. apodemi [1].

Fagerholm [20] reported that the precloacal median papilla in the males of genus Toxocara was simple and surrounded by a cuticle of bifid appearance. Sanmartín et al. [21] also indicated that the precloacal median papilla was highly variable in the genus Toxocara, but the cuticle of bifid appearance in T. genettae was not observed. In T. apodemi, Olsen [13] described that 12 to 14 pairs of pre-anal (precloacal) papillae and 6 pairs of post-anal (postcloacal) papillae are present, the posterior 3 pairs of the post-anal papillae being located on the lob-like terminal portion of the tail. The 3th, 4th, and 6th pairs of these papillae are laterally located, while the 2nd and 5th pairs are sub-ventral, the 2nd pair consisting of double papillae. The 1st pair is also on the ventral surface, but much closer to the lateral margin [13]. In this study, the 1st pair of postcloacal papilla numbered by Olsen [13] was located on the ventrolateral portion in front of cloaca, i.e., the papilla was precloacal papilla. Therefore, we numbered the 1st pair of postcloacal papilla from the double papillae, which was numbered the 2nd pair by Olsen [13], as the 1st pair of postcloacal papilla. Especially, the 3rd and 4th postcloacal papillae were closely associated with each other, and the 4th pair of post cloacal papillae were smaller than other papillae. The 4th pair of this study was not described by Olsen [13].

The precloacal median papilla and a single postcloacal median papilla were found in T. tanuki [11]. However, like T. indica [12], we did not observe the precloacal and postcloacal median papillae in the present study.

Sanmartín et al. [21] discussed that the eggs of T. genettae are similar in shape and surface structure to those of other members of the genus, and their size $(64-74 \times 50-54 \mu \mathrm{m})$ is similar to that of T. cati, and measurements of the superficial pits of egg $(4.8 \times 3.2 \mu \mathrm{m})$ are similar to those of T. canis, but slightly smaller. In this study, the size of egg (73-82 $\mu \mathrm{m})$ and the su- 
perficial pits of egg (mean $8.6 \times 6.7 \mu \mathrm{m}$ ) are obviously bigger than those of T. genettae, T. cati and T. canis.

For the identification of parasites, the 18S rRNA gene was analyzed as it is highly conserved and contains variable regions flanked by more conserved regions [18,22]. Although partial sequences of the $18 \mathrm{~S}$ rRNA gene of T. apodemi were similar to those of genus Toxocara, they were not perfectly matched with other members of Toxocara and a few unique variable regions were observed. Since there are not many sequences in the Toxocara clade, the morphology and gene of T. apodemi strongly support that this parasite is close to the Toxocara clade.

In conclusion, this is the first study to characterize T. apodemi using morphological features, SEM, and sequencing analysis. In SEM images, the cervical alae of T. apodemi was showed as the vestigial organs that looked like a slightly uplifted superficial sewing stitch. Also, we firstly found out the smaller 4th pair of postcloacal papilla, which is closely associated with 3rd papilla. In particular, the 3rd, 4th, and 5th pairs of postcloacal papilla is situated on the latero-dorsal surface than on the latero-ventral surface. The eggs of T. apodemi are easily distinguished from those of other Toxocara species by the bigger superficial pits. Although the partial $18 \mathrm{~S}$ rRNA sequence of $T$. apodemi showed high homology of other Toxocara species, we found that the sequence of $T$. apodemi is not totally matched with those of other Toxocara species. It was confirmed that ascarid nematodes, T. apodemi, recovered from striped field mice in Korea are taxonomically conspecific relationship with genus Toxocara and genetic divergence from other Toxocara species.

\section{ACKNOWLEDGMENT}

This research was supported by Basic Science Research Program through the National Research Foundation of Korea (NRF) funded by the Ministry of Education (Grant No. 2017RIDIAIB06031728) and supported by the Government-wide R\&D Fund for Infectious Diseases Research (HG18C0021) for the capture of mice.

\section{CONFLICT OF INTEREST}

The authors declare that there are no conflicts of interest.

\section{REFFERENCES}

1. Warren EG. Studies on the morphology and taxonomy of the genera Toxocara Stiles, 1905 and Neoascaris Travassos, 1927. Zool Anz 1970; 185: 393-442.

2. Hartwich G, Anderson RC, Chabaud AG, Willmott S. CIH Keys to the Nematode Parasites of Vertebrates. Farnham Royal, UK. Commonwealth Agricultural Bureaux. 1974, pp 1-15.

3. Gibbons LM, Jacobs DE, Sani RA. Toxocara malaysiensis n. sp. (Nematoda: Ascaridoidea) from the domestic cat (Felis catus Linnaeus, 1758). J Parasitol 2001; 87: 660-665.

4. Poulsen CS, Skov S, Yoshida A, Skallerup P, Maruyama H, Thamsborg SM, Nejsum P. Differential serodiagnostics of Toxocara canis and Toxocara cati--is it possible? Parasite Immunol 2015; 37: 204-207.

5. Le TH, Anh NTL, Nguyen KT, Nguyen NTB, Thuy DTT, Gasser RB. Toxocara malaysiensis infection in domestic cats in Vietnam-an emerging zoonotic issue? Infect Genet Evol 2016; 37: 94-98.

6. Asakawa M, Li JF, Guo AH, Yang XY, Huhebateer, Liu ZL, Liu Y, Cao XM, Chen KY. A new host and locality record for Toxocara apodemi (Olsen, 1957) (Nematoda: Ascarididae) from striped field mice, Apodemus agrarius (Pallas) (Rodentia: Murinae) in Changsha, China. J Rakuno Gakuen Univ Nt Sci 1994; 19: 193196.

7. Li K, Lan Y, Luo H, Zhang H, Liu D, Zhang L, Gui R, Wang L, Shahzad M, Sizhu S, Li J, Chamba Y. Prevalence, associated risk factors, and phylogenetic analysis of Toxocara vitulorum infection in yaks on the Qinghai Tibetan Plateau, China. Korean J Parasitol 2016; 54: 645-652.

8. Macchioni G. A new species, Toxocara lyncis, in the caracal (Lynx caracal). Parassitologia 1999; 41: 529-532.

9. Warren EG. Two new species of Toxocara from viverrid hosts. Parasitology 1972; 65: 179-187.

10. Liu D. Toxocara. In Liu D ed, Handbook of Foodborne Diseases. Boca Raton, USA. CRC Press 2018.

11. Alexander U, Lim CW, Kim B, Hong EJ, Kim HC, Park BK. Morphological and molecular characterization of Toxocara tanuki (Nematoda: Ascaridae) from Korean raccoon dog, Nyctereutes procyonoides koreensis. Korean J Parasitol 2018; 56: 567-575.

12. Naidu TSV. Two new ascarid nematodes from vertebrate hosts from India. Folia Parasitol 1981; 28: 327-334.

13. Olsen LS. A new species of Neoascaris (Nematoda) from a Korean wood mouse. Trans Am Microsc Soc 1957; 76: 205-208.

14. Hartwich G. Key to genera of the Ascaridoidea. In Anderson RC, Chaband AG, Willmott S eds, CIH Keys to the Nematode Parasites of Vertebrates, No. 2. Farnham Royal, UK. Commonwealth Agricultural Bureaux. 1974, pp 1-83.

15. Moreira GM, Telmo Pde L, Mendonça M, Moreira AN, McBride AJ, Scaini CJ, Conceição FR. Human toxocariasis: current advances in diagostics, treatment, and interventions. Trends Parasitol 2014; 30: 456-464.

16. Smith H, Holland C, Taylor M, Magnaval JF, Schantz P, Maizels R. How common is human toxocariasis? Towards standardizing our knowledge. Trends Parasitol 2009; 25: 182-188.

17. Chen J, Zhou DH, Nisbet AJ,Xu MJ, Haung SY, Li MW, Wang $\mathrm{CR}$, Zhu XQ. Advances in molecular identification, taxonomy, 
genetic variation and diagnosis of Toxocara spp. Infect Genet Evol 2012; 12: 1344-1348.

18. Hong EJ, Sim C, Chae JS, Kim HC, Park J, Choi KS, Yu DH, Yoo JG, Park BK. A horsehair worm, Gordius sp. (Nematomorpha: Gordiida), passed in a canine feces. Korean J Parasitol 2015; 53: 719-724.

19. Uga S, Matsuo J, Kimura D, Rai SK, Koshino Y, Igarashi K. Differentiation of Toxocara canis and T. cati eggs by light and scanning electron microscopy. Vet Parasitol 2000; 92: 287-294.

20. Fagerholm HP. Systematic implications of male caudal morphology in ascaridoid nematode parasites. Syst Parasitol 1991; 19: 215-229.
21. Sanmartín ML, Alvarez F, Gijón Botella H, Iglesias R, Estévez J, López-Román R. A scanning electron microscope study of Toxocara genette Warren, 1972 (Ascaridae), with data on morphometric variation. Folia Parasitol 1992; 39: 355-367.

22. Choi TI, Hong EJ, Ryu SY, Sim C, Chae JS, Kim HC, Park J, Choi KS, Yu DH, Yoo JG, Park BK. Detection and identification of Sarcocystis cruzi (Protozoa: Apicomplexa) by molecular and ultrastructural studies in naturally infected Korean cattle (Bos taurus coreanae) from Daejeon, Korea. Korean J Parasitol 2018; 56: 121-127. 
